\title{
MTHFR genetic polymorphism as a risk factor in Egyptian mothers with Down syndrome children
}

\author{
Nagwa A. Meguid ${ }^{\mathrm{a}, *}$, Ahmed A. Dardir ${ }^{\mathrm{a}}$, Mohamed Khass ${ }^{\mathrm{b}}$, Lamia El Hossieny ${ }^{\mathrm{b}}$, Afaf Ezzat $^{\mathrm{c}}$ and \\ Mostafa K. El Awady ${ }^{b}$ \\ ${ }^{a}$ Department of Research on Children with Special Needs, National Research Center, Cairo, Egypt \\ ${ }^{\mathrm{b}}$ Department of Biomedical Technology, National Research Center, Cairo, Egypt \\ ${ }^{\mathrm{c}}$ Department of Nutrition and Food Science, National Research Center, Cairo, Egypt
}

\begin{abstract}
Recent reports linking Down syndrome (DS) to maternal polymorphisms at the methylenetetrahydrofolate reductase $(M T H F R)$ gene locus have generated great interest among investigators in the field. The present study aimed at evaluation of MTHFR $677 \mathrm{C} / \mathrm{T}$ and 1298A/C polymorphisms in the MTHFR gene as maternal risk factors for DS. Forty two mothers of proven DS outcomes and forty eight control mothers with normal offspring were included. Complete medical and nutritional histories for all mothers were taken with special emphasis on folate intake. Folic acid intake from food or vitamin supplements was significantly low (below the Recommended Daily Allowance) in the group of case mothers compared to control mothers. Frequencies of MTHFR $677 \mathrm{~T}$ and MTHFR $1298 \mathrm{C}$ alleles were significantly higher among case mothers $(32.1 \%$ and $57.1 \%$, respectively) compared to control mothers ( $18.7 \%$ and $32.3 \%$, respectively). Heterozygous and homozygous genotype frequencies of MTHFR at position 677 (CT and TT) were higher among case mothers than controls $(40.5 \%$ versus $25 \%$ and $11.9 \%$ versus $6.2 \%$, respectively) with an odds ratio of 2.34 (95\% confidence interval [CI] 0.93-5.89) and 2.75 (95\% CI 0.95-12.77), respectively. Interestingly, the homozygous genotype frequency (CC) at position 1298 was significantly higher in case mothers than in controls (33.3\% versus $2.1 \%$ respectively) with an odds ratio of 31.5 (95\% CI 3.51 to 282.33 ) indicating that this polymorphism may have more genetic impact than 677 polymorphism. Heterozygous genotype (AC) did not show significant difference between the two groups. We here report on the first pilot study of the possible genetic association between DS and MTHFR 1298A/C genotypes among Egyptians. Further extended studies are recommended to confirm the present work.
\end{abstract}

Keywords: Methylenetetrahydrofolate reductase $(M T H F R)$, Down syndrome, polymorphism, MTHFR 677C/T polymorphism, MTHFR 1298A/C polymorphism, Egyptian

\section{Introduction}

Down syndrome is the most common genetic cause of human mental retardation, with a frequency of approximately 1 in 600 to 1000 live births [27]. It was estimated that 1 in 150 conceptions have trisomy 21

${ }^{*}$ Corresponding author: Prof. Nagwa A. Meguid, Prof. of Human Genetics \& Head of Department of Research on Children with Special Needs, National Research Center, Tahrir St., Cairo, Egypt. Tel.: +2012331 6372; Fax: +20 2337 0931, +20 2760 1877; E-mail: meguidna@yahoo.com. and that $80 \%$ of these are lost during early pregnancy [16]. The relationship between chromosomal nondisjunction and folate metabolism has drawn attention in recent years. Both folate and methylenetetrahydrofolate reductase $(M T H F R)$ are involved in many complex biochemical reactions. MTHFR is the enzyme responsible for the reduction of methylenetetrahydrofolate, which is a key single-carbon donor that takes part in nucleotide synthesis; S-adenosylmethionine (SAM) synthesis; remethylation of homocysteine to methionine; and the methylation of DNA, proteins, neurotransmitters, and phospholipids [17]. Altered mater- 
nal folate status and homozygous mutation in MTHFR gene may promote chromosomal instability and nondisjunction resulting in fetal trisomy 21 [18]. DNA hypomethylation induces structural alterations in pericentromeric heterochromatin and abnormal chromosome segregation. Reduced MTHFR activity results in an increased requirement for folic acid to maintain normal homocysteine remethylation to methionine. In the absence of sufficient folic acid, intracellular homocysteine accumulates, methionine resynthesis is reduced and remethylation reactions may be affected [22]. Research in this field has accelerated in the recent years, examining the relationship between DS and the two known gene polymorphisms, $M T H$ FR $677 \mathrm{C} / \mathrm{T}$ and MTRR 66A/G taking role in the folate pathway [15]. Studies by [17] have demonstrated a link between DS and MTHFR 677C/T and MTRR 66A/G polymorphisms. Maternal heterozygosity (CT) or homozygosity (TT) for MTHFR and homozygosity (GG) for MTRR have been calculated to increase the risk of having a child with DS. A second polymorphism 1298A/C involving alanine to cytosine nucleotide substitution in MTHFR gene has also been reported [30]. The purpose of the present study is to evaluate the role of MTHFR $677 \mathrm{C} / \mathrm{T}$ and 1298A/C polymorphisms in DS risk among Egyptian mothers.

\section{Subjects and methods}

\subsection{Subjects}

Forty two young mothers (less than 30 years old) with a previous history of bearing Down syndrome (DS) baby confirmed as regular trisomy 21 were selected from Children with Special Needs outpatient Clinic, National Research Center, Egypt. Forty eight control mothers, who resided in the same geographic area and almost the same social class and had given birth to at least two healthy children without history of any miscarriages or abnormal pregnancies, were included.

All subjects (mothers with DS children and control mothers) were subjected to:

1. Comprehensive history taking including pedigree analysis, family history of any genetic or nongenetic disorders, pregnancy history and obstetric history.

2. Dietary assessment: Quantitative daily consumption methods, consist recall and records designed to measure the quantity of the mother food and beverages consumed over 24 hours [12]. Dietary history and food frequency questionnaire were completed for all mothers with special emphasis on folate intake through food or vitamin supplements during pregnancy. Adequacy of the diet was assessed by comparing the energy and nutrient intake of mothers with their recommended daily allowances [8]. Comparison between the requirement of each mother according to FAO and the nutritive value of her food intake within 24 hours was done using Food Composition Tables of the National Nutrition Institute of Egypt [9].

\subsection{Sample collection}

Venous blood samples were collected on EDTA from all mothers and preserved at $4^{\circ} \mathrm{C}$ till assayed. Total genomic DNA was extracted from whole blood using salting out technique.

a-Polymerase Chain Reaction Amplification: Amplification was performed in $50 \mathrm{ul}$ reaction mixture containing approximately $100 \mathrm{ng}$ genomic DNA, $200 \mathrm{uM}$ dNTPS, 50 picomole of each forward and reverse primers, and 2 units of Taq DNA polymerase (Quiagene, Frankfurt, Germany) in a $1 \mathrm{X}$ buffer supplied with the enzyme containing $1.5 \mathrm{mM} \mathrm{MgCl} 2$.

For the polymorphic site $(\mathrm{C} \rightarrow \mathrm{T})$ at $677 \mathrm{bp}$, primer sequences used were derived from intron sequence bracketing exon (4) according to Kowa et al. [19].

Forward primer: 5'-TGA AGG AGA AGG TGT CTG CGG GA-3'

Reverse primer: 5'-AGG ACG GTG CGG TGA GAG TG-3'.

The primer sequences used for amplification of exon (7) were derived from inside exon (7) surrounding the polymorphic site $(\mathrm{A} \rightarrow \mathrm{C})$ at position 1298 . The primer design was performed using Primer3 Output Software (primer3_www_results.cgi) and the sequences were as follows:

Forward primer: '5 GAA GAG CAA GTC CCC CAA AG 3'

Reverse primer: '5 ACA GGA TGG GGA AGT CAC AC 3'

Thermal cycling and product detection: Initial denaturation for one cycle at $95^{\circ} \mathrm{C}$ for $3 \mathrm{~min}$. followed by 35 cycles each consisted of denaturation at $95^{\circ} \mathrm{C}$ for 30 seconds, annealing at $60^{\circ} \mathrm{C}$ for 45 seconds and extension at $72^{\circ} \mathrm{C}$ for one min. Amplification protocol was ended up with a final extension step at $72^{\circ} \mathrm{C}$ for 10 minutes. The PCR products were analyzed on $2 \%$ agarose gel electrophoresis and visualized by ethidium bromide staining. The detection of a fragment of 


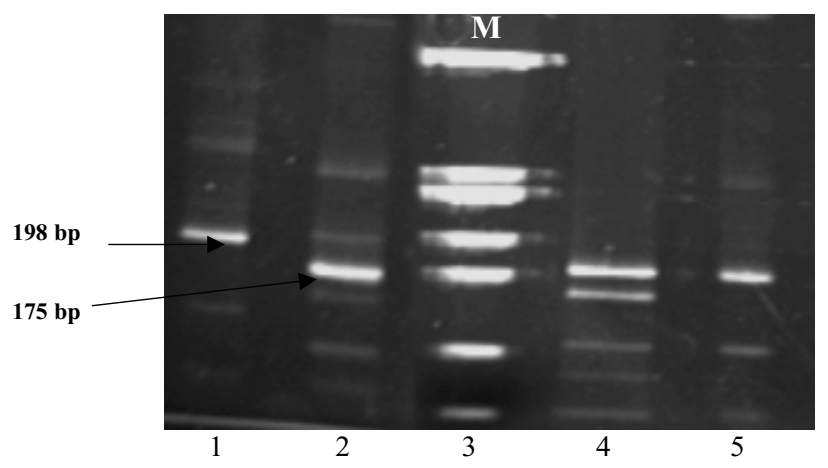

Fig. 1. Mutational analysis of MTHFR 677 polymorphism in exon 4. The amplified product (198 bp) was digested with Hinf I and the digested products were resolved on $20 \%$ polyacrylamide gel electrophoresis, stained with ethidium bromide and photographed on a photodocumentation system (Biometra, Germany). Lane 1 shows undigested 198 bp fragment. Lane 2 shows Hinf I digestion product of DNA from a mother of Down syndrome patient who is a homozygous for $\mathrm{C}$ to $\mathrm{T}$ (TT) polymorphism which displays doublet band at 175 bp besides 23 bp band (run off the gel). Lanes 4 displays 198 and 175 bp bands (heterozygous for C to T). Lane 5 shows a wild type (CC) with a doublet band at 198 bp. Band sizes were evaluated as a comparison with a molecular weight marker ØX174 Hae III digest (lane 3).

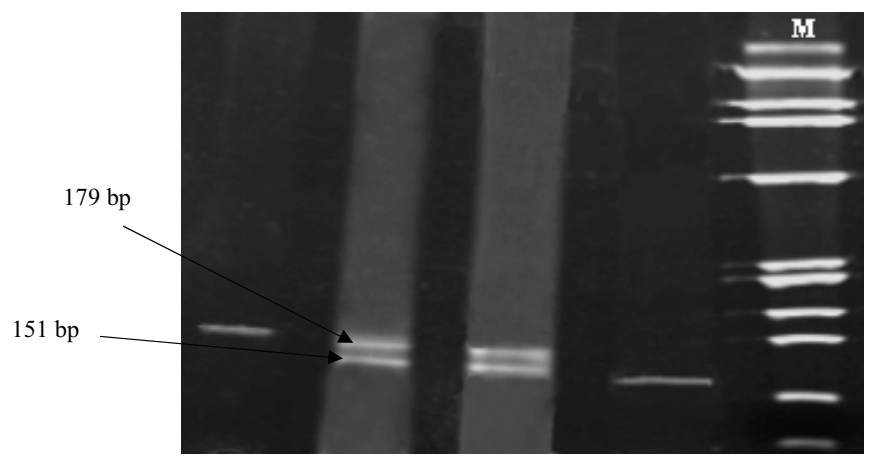

Fig. 2. Mutational analysis of MTHFR 1298 polymorphism in exon 7. The amplified product (221 bp) was digested with $M b o I I$ enzyme and the digested products were resolved on $20 \%$ polyacrylamide gel electrophoresis, stained with ethidium bromide and photographed on a photo documentation system (Biometra, Germany). Lane 2 and 3 show MboII digestion products of DNA from two mothers of Down syndrome patients who are heterozygous for A to C polymorphism which display two bands at 179 and 151 bp besides 30 and 28 bp bands (ran out of the gel). Lanes 1 and 4 display 179 and 151 bp bands respectively (homozygous mutant (CC) and homozygous wild type (AA) respectively). Band sizes were evaluated as a comparison with a molecular weight marker ØX174 Hae III digest (lane M).

198 bp indicates a successful amplification of exon 4 of human MTHFR gene (Fig. 1) and of a $221 \mathrm{bp}$ band indicates amplification of exon 7 (Fig. 2).

$b$ - Mutational analysis (Restriction fragment length polymorphism) of the digested PCR products: The digested products were resolved on $20 \%$ poly acrylamide gel. The poly acrylamide gel was stained with ethidium bromide and visualised with UV trans illuminator. The normal pattern (wild type) (CC) for exon (4) provides a single duplet band at $198 \mathrm{bp}$ after digestion with Hinf I. While the heterozygous pattern (CT) creates a Hinf I restriction site leading to the digestion of the $198 \mathrm{bp}$, providing three bands at 198, 175, and $23 \mathrm{bp}$. The $23 \mathrm{bp}$, last band is undetectable and ran out the gel. The mutant pattern (TT) provides 2 bands at 175, and
$23 \mathrm{bp}$. Only, one band at $175 \mathrm{bp}$ is detectable while that of $23 \mathrm{bp}$ ran out of gel (Fig. 1).

The $221 \mathrm{bp}$ of exon (7) is reduced to $209 \mathrm{bp}$ due to the presence of another MboII recognition site within the sequence of the forward primer which does not interfere with polymorphic site at $1298 \mathrm{bp}$, and that is used to detect whether the enzyme used is working or not. The normal pattern (wild type), (AA) for exon (7) provides 3 bands at 151, 30, and $28 \mathrm{bp}$, respectively after digestion with MboII. Only $151 \mathrm{bp}$ band is visualized on $20 \%$ polyacrylamide gel while the other two bands ran out of the gel. While, the heterozygous pattern (AC), (contains both mutant and wild type allele) provides 4 bands at 179, 151, 30, and $28 \mathrm{bp}$. The only two bands visualized on gel were 179 and $151 \mathrm{bp}$ while the other 2 bands ran out, as they are very small in size. 
The mutant pattern (CC) provided 2 bands at 179 and $30 \mathrm{bp}$ where only band at $179 \mathrm{bp}$ was visualized on the gel (Fig. 2).

\subsection{Statistical analyses}

Odds ratios and $95 \%$ confidence intervals $(95 \%$ CI) were calculated to estimate the risk of the different genotypes. Allele frequencies and genotype frequencies were calculated and the differences between mothers of children with DS and control mothers were determined using chi-square test. Expected genotype frequencies were calculated from the allele frequencies under the assumption of Hardy-Weinberg equilibrium. All statistical analyses were done with SPSS software, version 9.0. $\mathrm{P}$ values were two tailed, and $\mathrm{P}$ was considered statistically different if $\leqslant 0.05$.

\section{Results}

Detailed nutritional history revealed that $93 \%$ of case mothers did not receive folic acid vitamin supplement. Dietary content of folate in $90 \%$ of mothers included in this group was below the Recommended Daily Allowance, which is $400 \mu \mathrm{g} / \mathrm{d}$ [11], while the nutritional history taken from the control group showed folic acid supplementation (tablets of $5 \mathrm{mg}$ once per day) in $13 \%$ of cases, multivitamin supplement in $53 \%$ of cases, while adequate intake of vegetables (good sources of folic acid) was recorded in $67 \%$ of cases (Table 1). Student $\mathrm{T}$ test was performed on folate intake of mothers with D.S. children and control mothers and showed that folic acid intake was significantly lower in the group of mothers with D.S. children than in the control group $(P<0.01)$.

The distribution of the MTHFR genotypes in the control population was found to be in Hardy-Weinberg equilibrium. Frequencies of MTHFR 677T and $M T H$ FR $1298 \mathrm{C}$ alleles were significantly higher among case mothers $(32.1 \%$ and $57.1 \%$, respectively) compared to control mothers $(18.7 \%$ and $32.3 \%$, respectively) (Table 2).

The MTHFR $677 \mathrm{C} / \mathrm{T}$ genotype CC frequency was significantly higher among control mothers compared to case mothers $(68.8 \%$ and $47.6 \%$, respectively). The frequencies of MTHFR $677 \mathrm{C} / \mathrm{T}$ heterozygous and homozygous genotypes (CT and TT) were higher among case mothers $(40.5 \%$ and $11.9 \%$, respectively) than control mothers ( $25 \%$ and $6.2 \%$, respectively) with an odds ratios of 2.34 (95\% confidence interval [CI] 0.93-
5.89) and 2.75 (95\% CI 0.95-12.77), respectively. On the other hand, sum of both variant genotypes (CT plus TT) showed significant increase in case mothers compared to control group $(52.4 \%$ versus $31.2 \%$, respectively) with an odds ratio of 2.42 (95\% CI 1.02-5.72) (Table 3).

The frequency of MTHFR 1298 A/C genotype AA was higher among control mothers than case mothers with no statistically significant differences $(37.5 \%$ versus $19.1 \%$, respectively). However, the frequency of MTHFR $1298 \mathrm{~A} / \mathrm{C}$ homozygous genotype (CC) was significantly higher among case mothers than control mothers (33.3\% versus $2.1 \%$, respectively) with an odds ratio of 31.5 (95\% CI 3.51 to 282.33). Heterozygous genotype (AC) did not show significant difference between the two groups (47.6\% versus $60.4 \%$ respectively) with an odds ratio of 1.55 (95\% CI 0.57 to 4.26 ). Moreover, sum of both variant genotypes (AC plus CC) showed no significant difference between the case and control groups ( $80.9 \%$ versus $62.5 \%$ respectively) with an odds ratio of 2.55 (95\% CI 0.97-6.71) (Table 4).

\section{Discussion}

In most cases of DS, the extra chromosome exists as a result of the failure of normal chromosome segregation during meiosis. The non-disjunction event is maternal in $95 \%$ of cases, occurring primarily during meiosis 1 in the maturing oocyte before conception [18]. Although mechanisms described recently that could account for the meiotic non-disjunction are diverse, not a single mechanism could be referred to as prevailing. The risk of meiotic nondisjunction may be dependent on the interaction between different maternal polymorphisms 677C/T and 1298A/C of MTHFR, and 66A/G $M T R R$ genes together with nutrients interactions and lifestyle [20].

Nutritional history, as a possible risk factor, was considered in details to evaluate folate status of DS mothers in relation to control mothers. Folate acts as a cofactor for enzymes involved in DNA and RNA synthesis and in the supply of methyl group to the methylation cycle. Thus, folate deficiency can lead to defective cell proliferation and cell death [21]. Our results showed that folic acid intake was significantly lower than the Recommended Daily Allowance, which is $400 \mu \mathrm{g} / \mathrm{d}[11]$; in the group of case mothers compared to controls $(P<0.01)$.

MTHFR acts at a critical metabolic juncture in the regulation of cellular methylation reactions, catalyz- 
Table 1

Main dietary findings of mothers with DS children and control mothers

\begin{tabular}{lccc}
\hline Mothers & $\begin{array}{c}\text { Use of } \\
\text { Vitamin Supplements }\end{array}$ & $\begin{array}{c}\text { Folate from } \\
\text { Food }\end{array}$ & Number \\
\hline Control Mothers & $66 \%$ & $67 \%>400 \mu \mathrm{g} / \mathrm{d}$ & 48 \\
Case Mothers & $7 \%$ & $90 \%<400 \mu \mathrm{g} / \mathrm{d}$ & 42 \\
\hline
\end{tabular}

Table 2

Allele Frequency of $677 \mathrm{C} / \mathrm{T}$ and $1298 \mathrm{~A} / \mathrm{C}$ polymorphisms among case and control mothers

\begin{tabular}{cccccc}
\hline Genotype & Allele & $\begin{array}{c}\text { Case } \\
\text { mothers }(n=42) \\
\text { Alleles }\end{array}$ & $\begin{array}{c}\text { Control } \\
\text { Mothers }(n=48) \\
\text { Alleles }\end{array}$ & X & P \\
& & $\begin{array}{c}\text { (\%) }(n=84) \\
(\%)(n=96)\end{array}$ & & \\
\hline \multirow{2}{*}{677} & C & $57(67.9)$ & $78(81.3)$ & 4.29 & $\leqslant 0.05$ \\
& T & $27(32.1)$ & $18(18.7)$ & & \\
\multirow{2}{*}{1298} & A & $36(42.9)$ & $65(67.7)$ & 11.24 & $\leqslant 0.001$ \\
\hline
\end{tabular}

Table 3

Genotype Frequencies of MTHFR $677 \mathrm{C} / \mathrm{T}$ polymorphism in case and control mothers

\begin{tabular}{lcccccc}
\hline Genotype & $\begin{array}{c}\text { Number }(\% \text { of case } \\
\text { mothers }(n=42)\end{array}$ & $\begin{array}{c}\text { Number }(\%) \text { of control } \\
\text { mothers }(n=48)\end{array}$ & $\mathrm{X}^{2}$ & $\begin{array}{c}\text { Odds } \\
\text { ratio }\end{array}$ & 95\% CI & $\mathrm{P}$ \\
\hline CC & $20(47.6)$ & $33(68.8)$ & 4.13 & 1.0 & & $\leqslant 0.05$ \\
CT & $17(40.5)$ & $12(25.0)$ & 2.46 & 2.34 & $0.93-5.89$ & NS \\
TT & $5(11.9)$ & $3(6.2)$ & 0.88 & 2.75 & $0.59-12.77$ & NS \\
Combined mutant & $22(52.4)$ & $15(31.2)$ & 4.13 & 2.42 & $1.02-5.72$ & $\leqslant 0.05$ \\
(CT plus TT) & & & & & & \\
\hline
\end{tabular}

NS: non-significant.

Table 4

Genotype frequencies of MTHFR 1298 A/C polymorphism in case and control mothers

\begin{tabular}{lcccccc}
\hline Genotype & $\begin{array}{c}\text { Number }(\%) \text { of case } \\
\text { mothers }(n=42)\end{array}$ & $\begin{array}{c}\text { Number }(\%) \text { of } \\
\text { control mothers }(n=48)\end{array}$ & $\begin{array}{c}\text { Odds } \\
\text { ratio }\end{array}$ & 95\% CI & $\mathrm{X}^{2}$ & $\mathrm{P}$ \\
\hline AA & $8(19.1)$ & $18(37.5)$ & 1.0 & & 3.71 & $\mathrm{NS}$ \\
$\mathrm{AC}$ & $20(47.6)$ & $29(60.4)$ & 1.55 & $0.57-4.26$ & 1.48 & $\mathrm{NS}$ \\
CC & $14(33.3)$ & $1(2.1)$ & 31.5 & $3.51-282.33$ & 15.75 & $\leqslant 0.001$ \\
Combined mutant & $34(80.9)$ & $30(62.5)$ & 2.55 & $0.97-6.71$ & 3.71 & $\mathrm{NS}$ \\
(C plus CC) & & & & & & \\
\hline NS: non-significant. & & & & & &
\end{tabular}

ing the conversion of 5,10-methylenetetrahydrofolate to 5-methyltetrahydrofolate, the methyl donor for the remethylation of homocysteine to give methionine [4].

Frequent mutations may modify enzymatic activity. The specific activity of MTHFR is low in the heterozygous genotype and in the homozygous mutant genotype. Reviewing the literature, many polymorphisms have been identified in MTHFR gene. However, two most common genetic polymorphisms associated with a reduced MTHFR activity have been identified. One is located in exon 4 at the folate-binding site $(677 \mathrm{C} / \mathrm{T})$. The cytosine to thymine transition mutation at position 677 within the MTHFR gene $(677 \mathrm{C} / \mathrm{T})$ causes an alanine to valine substitution in the MTHFR protein and reduced enzyme activity [10]. In homozygous TT subjects, this mutation results in approximate- ly $50 \%$ of enzyme activity compared to those without mutation and leads to decreased synthesis of 5methyltetrahydrofolate. Among healthy subjects, the homozygous TT genotype is associated with a significantly higher homocysteine and low red cell folate levels than in heterozygotes or individuals with wild type C alleles. The (1298A/C) polymorphism is located in exon 7 within the presumptive regulatory domain [13]. It involves adenosine to cytosine nucleotide substitution in MTHFR gene resulting in a glutamine to alanine substitution [30]. The mutation destroyed an $\mathrm{MboII}$ recognition site and had an allele frequency of 0.33 . The $1298 \mathrm{~A} \rightarrow \mathrm{C}$ mutation results in decreased MTHFR activity, which was more pronounced in the homozygous than heterozygous state [29]. 
T-allele frequency for $677 \mathrm{C} / \mathrm{T}$ mutation of $M T H F R$ gene in the Egyptian control group established by the present study $(18.7 \%)$ is much similar to that reported in UK (18.6\%), lower compared to USA (32.2\%) and higher when compared to Sri Lanka $(4.9 \%)$ and South India $(10 \%)[7,26]$. Moreover, we found that frequency of MTHFR 677T allele was significantly higher among case mothers $(32.1 \%)$ compared to control mothers. The present study showed that frequencies of MTHFR 677C/T; either heterozygous (CT) or homozygous (TT) genotypes were higher among case mothers ( $40.5 \%$ and $11.9 \%$ respectively) than control mothers ( $25 \%$ and $6.2 \%$ respectively) with an odds ratios of 2.34 and 2.75 , respectively. The sum of both variant genotypes (CT plus TT) showed significant increase in case mothers compared to control mothers $(52.4 \%$ versus $31.2 \%$ respectively). Many studies pointed to the role of maternal MTHFR $677 \mathrm{C} / \mathrm{T}$ polymorphism as a risk factor for Down syndrome. James et al. [18] found a higher frequency of both the MTHFR CT and TT genotype in the mothers of children with DS as compared to control mothers which is consistent with our results. Another subsequent similar study by Hobbs et al. [17] have shown data consistent with the preliminary observation of MTHFR $677 \mathrm{C} / \mathrm{T}$ polymorphism in mothers with DS children than among controls with an odd ratio of 1.91. Moreover Acacio [1] in Brazil found that the frequency of joint heterozygotic polymorphism $677 \mathrm{C} / \mathrm{T}$ of $M T H F R$ gene was significantly higher in 70 women with children affected by trisomy 21 than in 88 controls with normal offspring. In a study from India, where 677T allele frequency is quite low in the population Rai et al. [23] have shown a strong association of this SNP, especially the T homozygote, with DS mothers. Interestingly, the $\mathrm{T}$ homozygous case mothers were all younger than 30 years of age. These authors have attributed 677TT as a genetically predisposing factor for susceptibility of young mothers to DS in this population.

Other studies done on Italian and French mothers did not support the presence of an increased risk of DS birth in mothers with 677T allele of MTHFR gene [4,22,28]. They reported that, the high intake of food folate in France and Italy may neutralize the metabolic impact of the MTHFR polymorphism. Moreover Tanamandra et al. [31] reported no correlation of MTHFR mutant 677TT homozygosity or mutant $677 \mathrm{~T}$ allele frequency with prenatal Down syndrome Caucasian cases. A recent study done by Copped et al. [5] on 80 Italian mothers of DS individuals and 111 Italian control mothers showed that MTHFR $677 \mathrm{C} / \mathrm{T}$ polymorphism was an in- dependent risk factor for a DS offspring at a young maternal age; however, a role for the combined MTHFR folate carrier gene ( $R F C$ - 1$)$ genotypes in the risk of DS pregnancies among young Italian women could not be excluded. They reported that MTHFR 1298A/C genotype frequencies did not significantly differ between DS mothers and control mothers when polymorphisms were considered alone, however, the combined $M T H$ $F R$ AA /RFC-1 80(GA or AA) genotypes was inversely associated with the risk of DS pregnancies among young Italian women.

In the present study, the frequency of the $1298 \mathrm{C}$ allele frequency in the Egyptian control group was $32.3 \%$ which is relatively lower than those reported in the Japanese and Africans who had $79 \%$ and $91 \%$ frequencies respectively [24]. Moreover, our results showed that the frequency of MTHFR $1298 \mathrm{C}$ allele was significantly higher among case mothers $(57.1 \%)$ compared to controls $(32.3 \%)$.

Regarding the MTHFR $1298 \mathrm{~A} / \mathrm{C}$ polymorphism in the present study; frequency of homozygous genotype (CC) was significantly higher among case mothers than controls (33.3\% versus $2.1 \%$ respectively). Heterozygous genotype (AC) did not show statistically significant difference between the two groups. The sum of both variant genotypes (AC and CC) was higher among case group compared to control group with no significant difference between the two groups $(80.9 \%$ versus $62.5 \%$ respectively). Similar results were reported by Grillo et al. [14], who evaluated the frequency of the MTHFR $1298 \mathrm{~A} \rightarrow \mathrm{C}$ mutations in 36 mothers of children with DS and in 200 controls. They reported that the MTHFR $1298 \mathrm{~A} \rightarrow \mathrm{C}$ mutations were more prevalent among mothers of children with DS than controls. Moreover Scala et al. [25] investigated 94 mothers of DS offspring and 264 control women from Campania, Italy. They reported an increased risk of DS associated with MTHFR $1298 \mathrm{C}$ allele and the MTHFR $1298 \mathrm{CC}$ genotype. However, the study done by da Silva et al.[6] on Brazilian mothers and Boduroglu et al. [2] on Turkish mothers did not find any association between MTHFR 1298A/C polymorphism and the risk for Down syndrome.

Castro et al. [3] suggested that the 1298CC MTHFR genotype, independently of folate availability, might be potential risk factors for disease states associated with DNA hypomethylation status including cancer. Moreover, The involvement of the $1298 \mathrm{~A}>\mathrm{C}$ variant in the development of neural tube defects has only been considered in a few studies which report a tendency towards a higher frequency in neural tube defective children [30]. 
Hassold et al. [15] reported that polymorphism variability in the folate pathway is not a significant contributor factor for human meiotic nondisjunction. They suggested that factors involving, both genotype and nutrition may underlie susceptibility to nondisjunction involving chromosome 21 but the same may not be true for other autosomal trisomies. Therefore geneticenvironmental interactions will continue to be unmasked as an increasing number of genes involved in folate metabolism is cloned. We concluded that $M T H$ FR gene polymorphisms may be associated with maternal risk for DS. For adequate functioning of $M T H$ $F R$ enzyme in mutants; both in heterozygous and homozygous conditions; folate supplementation would be helpful.

\section{References}

[1] G.L. Acacio, R. Barini, C.S. Bertuzzo, E.C. Couto, J.M. Annichino-Bizzacchi and W.P. Junior, Methylenetetrahydrofolate reductase gene polymorphisms and their association with trisomy 21, Prenat Diagn 25(13) (2005), 1196-1199.

[2] K. Boduroglu, Y. Alanay, B. Koldan and E. Tuncbilek, Methylenetetrahydrofolate Reductase Enzyme Polymorphisms as Maternal Risk for Down Syndrome Among Turkish Women, American Journal of Medical Genetics A 127 (2004), 5-10.

[3] R. Castro, I. Rivera, P. Ravasco, M.E. Camilo, C. Jakobs, H.J Blom and I.T. de Almeida, 5,10-Methylenetetrahydrofolate reductase (MTHFR) 677C-T and 1298A-C mutations are associated with DNA hypomethylation, J Med Genet 41 (2004), 454-458.

[4] B. Chadefaux-Vekemans, M. Coudé, F. Muller, J.F. Oury, A. Chabli, J.P. Ja'Is and P. Kamoun, Methylenetetrahydrofolate Reductase Polymorphism in the Etiology of Down Syndrome, Pediatric Research 51(6) (2002), 766-767.

[5] F. Coppede, G. Marini, S. Bargagna, L. Stuppia, F. Minichilli, I. Fontana, R. Colognato, G. Astrea, G. Palka and L. Migliore, Folate gene polymorphisms and the risk of Down syndrome pregnancies in young Italian women, Am J Med Genet A 140(10) (2006), 1083-1091.

[6] L.R. da Silva, N. Vergani, C. Galdieri Lde, M.P. Ribeiro Porto, S.B. Longhitano, D. Brunoni, V. D'Almeida and A.B. Alvarez Perez, Relationship between polymorphisms in genes involved in homocysteine metabolism and maternal risk for Down syndrome in Brazil, Am J Med Genet A 135(3) (2005), 263-267.

[7] A.R. Devi, V. Govindaiah, G. Ramakrishna and S.M. Naushad, Prevalence of methylene tetrahydrofolate reductase polymorphism in South Indian population, Current Science 86(3) (2004), 440-443.

[8] FAO/WHO/UNU (1985), Energy and protein requirements. Report of a joined FAO/WHO/UNU Expert Consultation. World Health Organization. Geneva.

[9] Food Composition Tables of National Nutrition Institute of Egypt, 1993: Based on local food analysis and food composition tables in the Middle East.
[10] P. Frosst, H.J. Blom, R. Milos, P. Goyette, C.A. Sheppard, R.G. Matthews, G.J.H. Boers, M. den Heijer, L.A.J. Kluijtmans, L.P. van den Heuvel and R. Rozen, A candidate genetic risk factor for vascular disease: a common mutation in methylenetetrahydrofolate reductase, Nature Genet 10 (1995), 111-113.

[11] S. Gerrior and C. Zizza, Nutrient content of the U.S. Food Supply, Home Economics Research Report No.52., Department of Agriculture, Washington, USA, 1994, 88.

[12] S.R. Gibson, Principle of Nutritional Assessment, New York, Oxford; Oxford University Press, 1990.

[13] P. Goyette, P. Aditya, M. Renate, P. Frosst, P. Tran and Z. Chen, Gene structure of human and mouse methylenetetrahydrofolate reductase (MTHFR), Mammalian Genome 9 (1998), 652-656.

[14] L.B. Grillo, G.L. Acacio, R. Barini, W. Pinto Jr. and C.S. Bertuzzo, Mutations in the methylene-tetrahydrofolate reductase gene and Down syndrome, Cad Saude Publica 18(6) (2002), 1795-1797.

[15] T.J. Hassold, L.C. Burrage, E.R. Chan, L.M. Judis, S. Schwartz, S.J. James, P.A. Jacobs and N.S. Thomas, Maternal folate polymorphisms and the etiology of human nondysjunction, Am J Hum Genet 69 (2001), 434-439.

[16] D. Hernandez and E.M.C. Fisher, Down syndrome genetics: unravelling a multifactorial disorder, Hum Mol Genet 5 (1996), 1411-1416.

[17] C.A. Hobbs, S.L. Sherman, P. Yi, S.E. Hopkins, C.P. Torfs, R.J. Hine, M. Pogribna, R. Rozen and S.J. James, Polymorphisms in genes involved in folate metabolism as maternal risk factors for Down syndrome, Am J Hum Genet 67 (2000), 623-630.

[18] S.J. James, M. Pogribna, I.P. Pogribny, S. Melnyk, R.J. Hine, J.B. Gibson, P. Yi, D.L. Tafoya, D.H. Swenson, V.L. Wilson and D.W. Gaylor, Abnormal folate metabolism and mutation in the methylenetetrahydrofolate reductase gene may be maternal risk factors for Down syndrome, Am J Clin Nutr 70 (1999), 495-501.

[19] H. Kowa, K. Yasui, T. Takeshima, K. Urakami, F. Sakai and K. Nakashima, The homozygous C677T mutation in the methylenetetrahydrofolate reductase gene is a genetic risk factor for migraine, Am J Med Genet 96(6) (2000), 762-764.

[20] M.L. Martinez-Frias, B. Perez, L.R. Desviat, M. Castro, F. Leal, L. Rodriguez, E. Mansilla, M.L. Martinez-Fernandez, E. Bermejo, E. Rodriguez-Pinilla, D. Prieto and M. Ugarte, ECEMC Working Group (2006): Maternal polymorphisms 677C-T and 1298A-C of MTHFR, and 66A-G MTRR genes: is there any relationship between polymorphisms of the folate pathway, maternal homocysteine levels, and the risk for having a child with Down syndrome? Am J Med Genet A 140(9) (2006), 987-997.

[21] M. Mooij, T. Steegers, C. Thomas, W. Doesburg and T. Eskes, Periconceptional vitamin profiles are not suitable for identifying women at risk for neural tube defects, J Nutri 123 (1993), 197-203.

[22] V.B. O’Leary, A. Parlie-McDermott, A.M. Molloy, P.N. Kirke, Z. Johnson and M. Colney, MTRR and MTHFR polymorphism; Link to Down syndrome, Am J Med Genet 107 (2002), 151-155.

[23] A.K. Rai, S. Singh, S. Mehta, A. Kumar, L.K. Pandey and R. Raman, MTHFR C677T and A1298C polymorphisms are risk factors for Down's syndrome in Indian mothers, J Hum Genet 51 (2006), 278-283.

[24] N. Rosenberg, M. Murata, Y. Ikeda, O. Opare-Sem, A. Zivelin, E. Geffen and U. Seligsohn, The Frequent 5,10Methylenetetrahydrofolate Reductase C677T Polymorphism 
Is Associated with a Common Haplotype in Whites, Japanese, and Africans, Am J Hum Genet 70 (2002), 758-762.

[25] I. Scala, B. Granese, M. Sellitto, S. Salome, A. Sammartino, A. Pepe, P. Mastroiacovo, G. Sebastio and G. Andria, Analysis of seven maternal polymorphisms of genes involved in homocysteine/folate metabolism and risk of Down syndrome offspring, Genet Med 8(7) (2006), 409-416.

[26] J.A. Schneider, D.C. Rees, Y.T. Liu and J.B. Clegg, Worldwide distribution of a common methylenetetrahydrofolate reductase mutation, Am J Hum Genet 62(5) (1998), 1258-1260.

[27] G. Smith and J. Berg, Down's anomaly. 2nd ed. Churchill Livingstone, Edinburgh and New York.

[28] L. Stuppia, V. Gatta, A.R. Gaspari, I. Antonucci, E. Morizio, G. Calabrese and G. Palka, C677T mutation in the 5,10MTHFR gene and risk of Down syndrome in Italy, Eur J Hum Genet 10 (2002), 388-390.
[29] N.M. van der Put, F. Gabreels, E.M. Stevens, J.A.M. Smeitink, F.J.M. T.K.A.B. Trijbels, T.K.A.B. Eskes, L.P. van den Heuvel and H.J. Blom, A second common mutation in the methylenetetrahydrofolate reductase gene: an additional risk factor for neural tube defects? Am J Hum Genet 62 (1998), 1044-1051.

[30] I. Weisberg, P. Tran, B. Christensen, S. Sibanis and R. Rozen, A second genetic polymorphism in methylenetetrahydrofolate reductase (MTHFR) associated with decreased enzyme activity, Mol Genet Metab (1998), 169-172.

[31] K. Yanamandra, J.A. Bocchini Jr. and T.F. Thurmon, Absence of association of fetal MTHFR C677T polymorphism with prenatal Down syndrome pregnancies, Europ J Hum Genet 11 (2003), 5. 


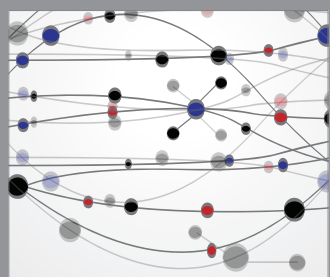

The Scientific World Journal
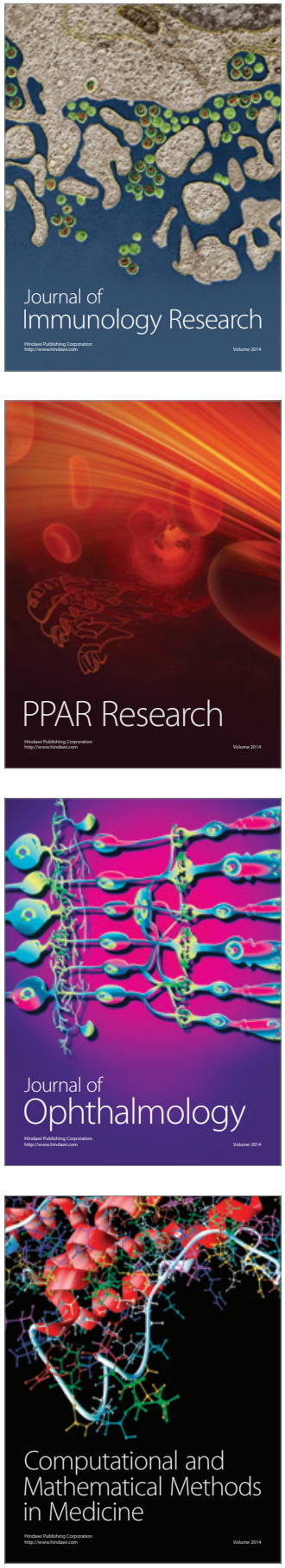

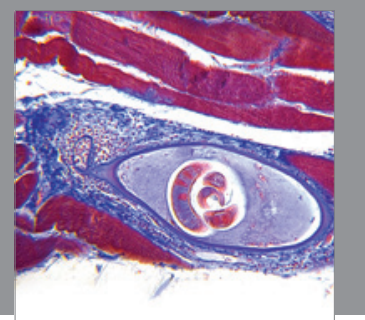

Gastroenterology

Research and Practice
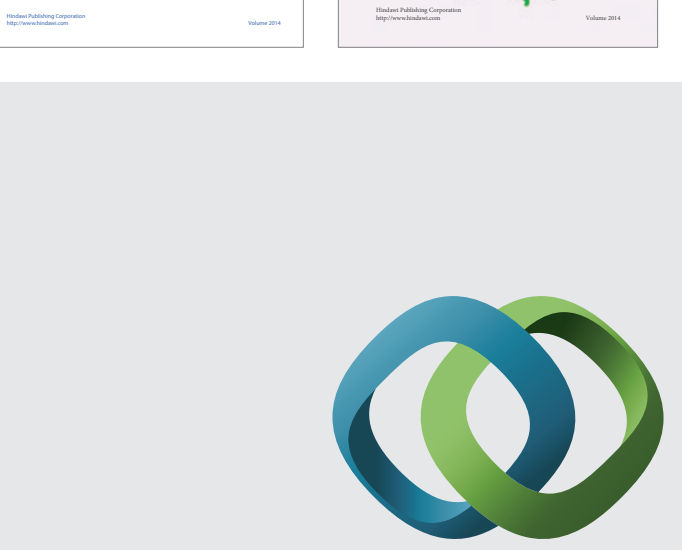

\section{Hindawi}

Submit your manuscripts at

http://www.hindawi.com
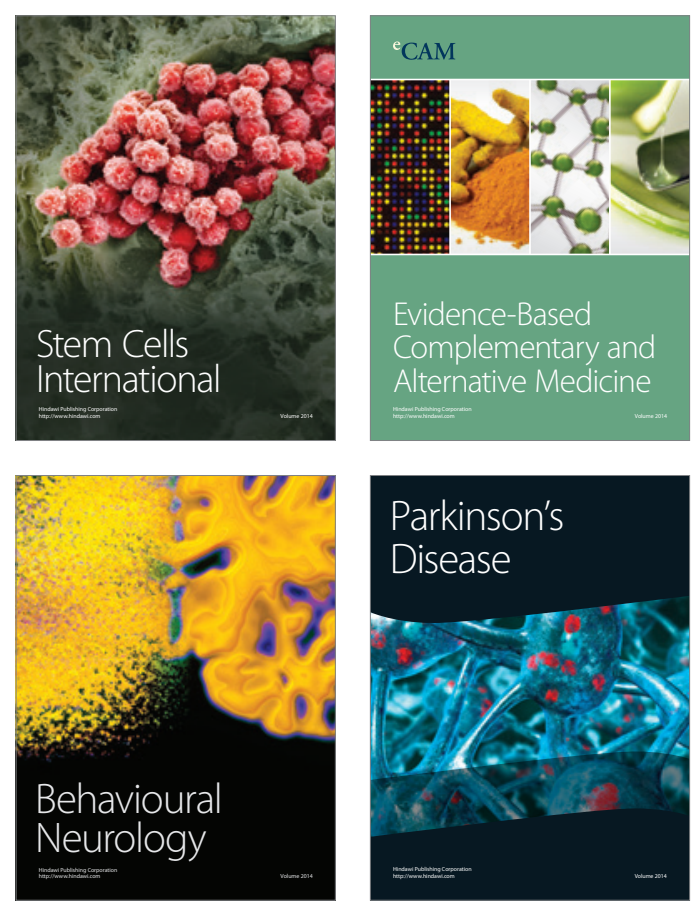

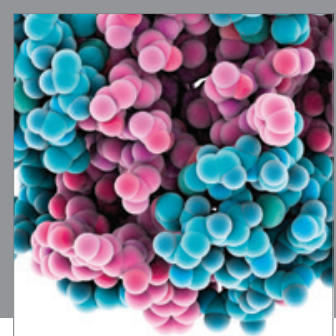

Journal of
Diabetes Research

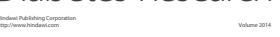

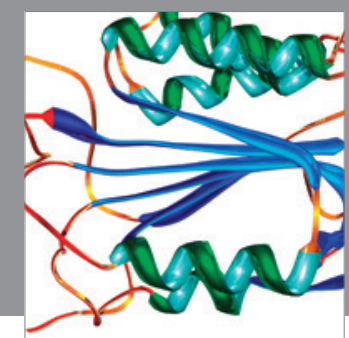

Disease Markers
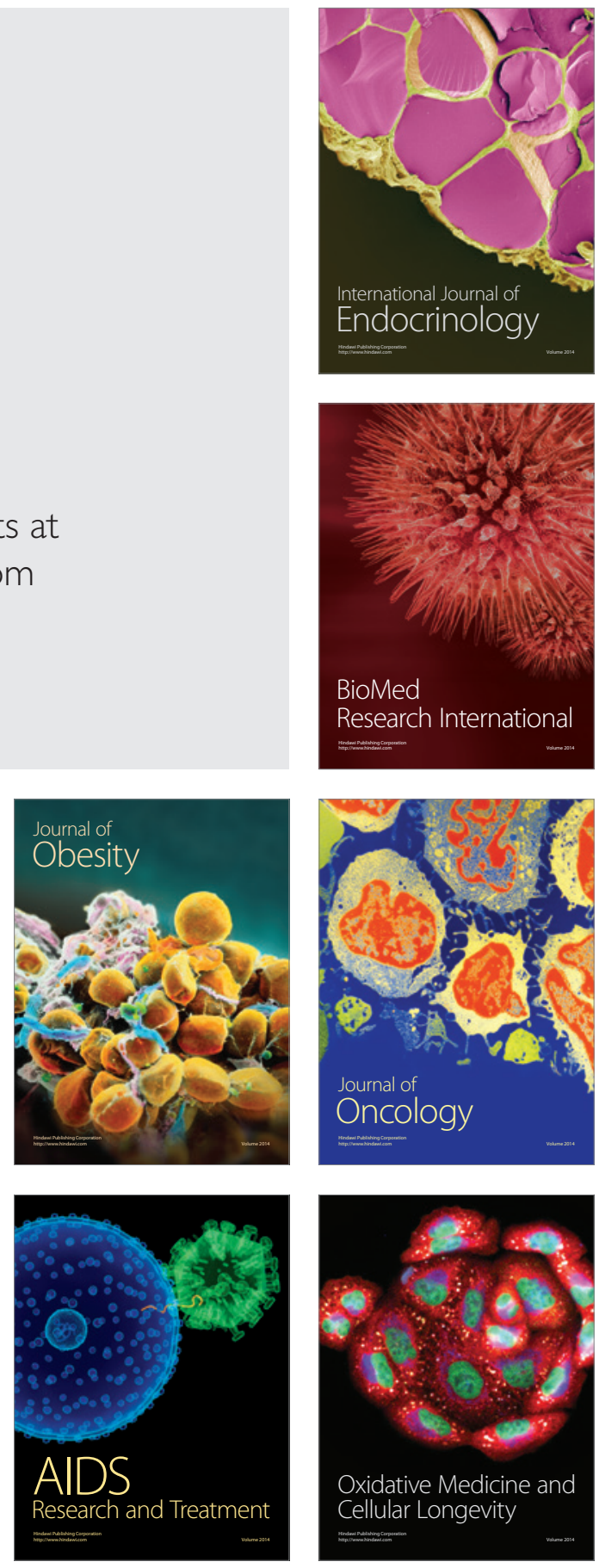